\title{
RANDOMISATION, AND AN OLD ENIGMA OF CARD PLAY.
}

\author{
By R. A. Fisher.
}

THE process of randomisation has in recent years come to play such a central part in experimental design that it is of some interest to find that it affords a means of resolving one of the oldest paradoxes which arose in discussions of gaming.

Readers of Todhunter's The Mathematical Theory of Probability will recall his account (sections 187-190, pp. 106-110) of the correspondence between Montmort and Nicolas Bernoulli on the rule by which the players might guide themselves most advantageously in the game called "le Her".

In the game, when played by two persons, the dealer $A$ deals himself and his opponent $B$ a single card each, the cards being valued in order from the ace as lowest to the king as highest. First $B$ has the option, if he wishes it, to change his card with that which $A$ holds, but if $A$ holds a king, he is allowed to retain it. Next $A$, whether the cards are changed or not, has the option of interchanging his with one chosen at random from the pack, but if he draws a king he must retain his original card. It is a convention of the game that if the two cards finally held are equal $A$ is the winner.

It being understood * that $B$ will change any card lower that 7 , and will retain any card of higher value, and that, if $B$ does not exercise his option, $A$ will change any card lower than an 8 and retain any higher card, the questions which Montmort's discussion was intended to resolve were whether $B$ should exercise his option when he holds a 7 , and whether $A$ should do so when he holds an 8 .

The paradoxical point which led to the dispute lies in the facts, which can be shown by simply counting the chances, that if it is $B$ 's rule to change a 7 , then $A$ will gain by adopting the rule of changing his 8 , and vice versa. It is to $A$ 's advantage to follow a like rule with $B$. But, if it is $A$ 's rule to change his 8 , then it is to $B$ 's advantage to retain his 7 , while, in the contrary case, he would gain by changing it. It is thus to $B$ 's advantage to act on a rule unlike that of $A$. It was Nicolas Bernoulli's view that both players ought to change in the doubtful cases, while Montmort held that no absolute rule could be given.

Montmort's conclusion, though obviously correct for the limited aspect in which he viewed the problem, is unsatisfactory to common sense, which suggests that in all circumstances there must be, according to the degree of our knowledge, at least one rule of conduct which shall be not less satisfactory than any other : and this his discussion fails to provide. Granted that if $B$ knows $A$ 's rule he can most advantageously adopt an unlike rule for himself, this does not answer the question: How should $B$ act if he does not know $A$ 's

\footnotetext{
* Todhunter does not discuss these preliminary points, but speaks of them as "tacitly allowed by the disputants" ; it is, however, demonstrable that these rules are advantageous to the players who follow them.
} 
rule, but feels instead justified in presuming that $A$ 's conduct will be guided by his own advantage?

This question, which is left untouched by the discussions of Montmort and Todhunter, may be resolved by the simple consideration that there are more than two rules for $B$ to choose from. He may always change a 7 when he has it, or he may never change it, but, again, he may adopt the rule of changing it occasionally, with a definitely chosen frequency. There will, so far as the mathematical problem is concerned, be nothing to guide him as to when to change and when to retain his card, but without such guidance he may, none the less, adopt such a policy as changing once in every three trials at haphazard, or with any other frequency preferred. The same is true of $A$, and we may. follow out the consequences of the supposition that $A$ chooses a frequency, $p$, for changing his 8 , and $B$ a frequency, $p^{\prime}$, for changing his 7 .

Knowing the manner in which the players exercise their options, it is easy to calculate $B$ 's chance of winning in each of the $13 \times 13$ ways in which the cards can be originally dealt. Thus, if $A$ has dealt his opponent an ace, and himself a 2 , the cards will certainly be changed, and $A$, receiving an ace, will exercise his option of choosing another from the pack. $B$ 's chance of winning rests on the possibility that, out of the 50 cards available, $A$ shall choose either one of the three remaining aces or one of the four kings. His probability of winning is therefore $\frac{7}{50}$. The table below shows the chances out of 50 for all possible cases. There are separate columns, when $B$ receives a 7, for the cases of his changing and retaining it respectively,

Table showing NUMBer of CHaNCES OUT OF 50 FaVOURABLE TO $B$, FOR ALL COMBINATIONS OF CARDS ORIGINALLY HELD.

\begin{tabular}{|c|c|c|c|c|c|c|c|c|c|c|c|c|c|c|}
\hline & & & & & & & 's c & & & & & & & \\
\hline & 1 & 2 & 3 & 4 & 5 & 6 & & 7 & 8 & 9 & 10 & $\mathrm{~J}$ & $\mathrm{Q}$ & $\mathrm{K}$ \\
\hline & & & & & & & & & & & & & & \\
\hline 1 & 0 & 0 & 0 & 0 & 0 & 0 & 0 & $2^{7} 7$ & 31 & 35 & 39 & 43 & 47 & 50 \\
\hline 2 & 7 & 0 & 0 & 0 & 1 & 0 & 0 & 27 & 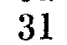 & 5 & & 43 & 47 & 50 \\
\hline 3 & 11 & 11 & 0 & 0 & & 0 & 0 & 27 & 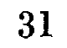 & 5 & $\begin{array}{l}9 \\
\text { s. }\end{array}$ & 4 & 47 & 50 \\
\hline 4 & 15 & 15 & 15 & 0 & ( & 0 & 0 & 27 & 31 & 5 & 39 & 43 & 47 & 50 \\
\hline$\tilde{\delta}$ & 19 & 19 & 19 & 19 & 0 & 0 & 0 & 2 & 3 & 35 & 9 & 43 & 47 & 50 \\
\hline 6 & 23 & 23 & 23 & 23 & 23 & 0 & 0 & 2 & 31 & 35 & 39 & 43 & 47 & 50 \\
\hline 7 & 27 & 27 & 27 & 27 & 27 & 27 & 0 & 24 & 31 & 35 & 39 & 43 & 47 & 50 \\
\hline 8 & 31 & 31 & 31 & 31 & 31 & 31 & 31 & ; 24 & 28 & 35 & 39 & 43 & 47 & $50 p$ \\
\hline 0 & $s_{1}$ & $J 1$ & 31 & 51 & 31 & 01 & 31 & 10 & 0 & 50 & 50 & 50 & 50 & 50 \\
\hline 9 & 35 & 35 & 3 & 35 & 3 & 35 & 35 & 0 & 0 & 0 & 50 & 50 & 50 & 50 \\
\hline 10 & 39 & 39 & ? & 3 & 39 & 39 & 3 & 0 & 0 & 0 & 0 & 50 & 50 & 50 \\
\hline $\mathrm{J}$ & 4 & 43 & 4 & 4 & 4 & 3 & 43 & 0 & 0 & 0 & 0 & 0 & 50 & 50 \\
\hline$Q$ & 47 & 47 & 47 & 47 & 47 & 47 & 47 & 0 & 0 & 0 & 0 & 0 & 0 & 50 \\
\hline $\mathrm{K}$ & 0 & 0 & 0 & 0 & 0 & 0 & 0 & 0 & 0 & 0 & 0 & 0 & 0 & 0 \\
\hline
\end{tabular}


and separate lines, when no interchange has been made, for the cases of $A$ changing and retaining his 8 . With respect to the frequency of the different cases it should be noted, apart from the frequencies assigned to the exercise of the two options, that the cases in which the opponents have initially cards of different value each occur 16 times in $52 \times 51$ trials, while those in which they have the same value occur only 12 times.

In all it appears that, out of 5525 games, $B$ 's expectation of winning is $2828+6 p+10 p^{\prime}-16 p p^{\prime}$. If, therefore, he fixes on any frequency $p^{\prime}$ greater than $\frac{3}{8}$, his opponent, if he, $A$, acts to his own greatest advantage, will put $p=1$, so minimising $B$ 's expectation at the value $2834-6 p^{\prime}$. If, on the other hand, he chooses a value of $p^{\prime}$ less than $\frac{3}{8}$, his opponent, if he acts to his own advantage, will put $p=0$, so minimising the expectation at the value $2828+10 p^{\prime}$. It is now clear how $B$ should act to his own greatest advantage, for the function (Fig. 1) :

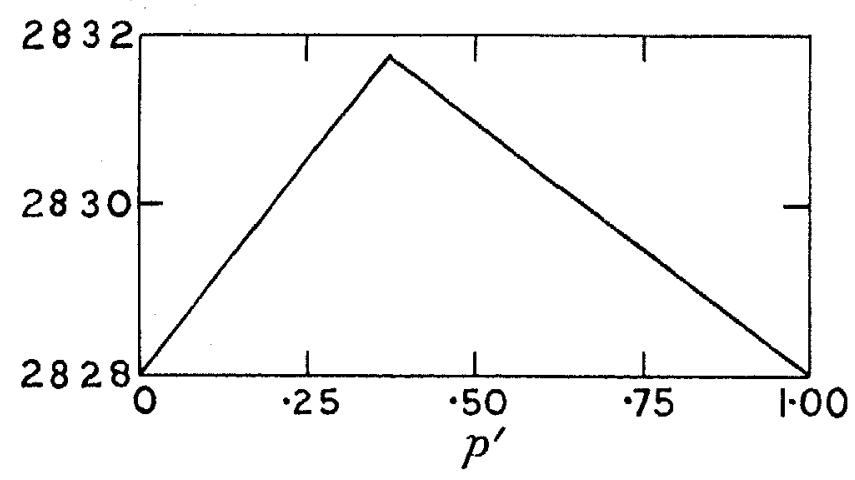

Fia. 1.

Minimal expectation of $B$ for different values of $p^{\prime}$.

$$
\begin{array}{ll}
2828+10 p^{\prime}, & 0 \leqslant p^{\prime} \leqslant \frac{3}{8}, \\
2834-6 p^{\prime}, & \frac{3}{8} \leqslant p^{\prime} \leqslant 1,
\end{array}
$$

has its greatest value, $2831 \cdot 75$, when $p^{\prime}=\frac{3}{8}$. $B$ should, therefore, change his 7 at random three times out of eight, and it is then indifferent to him what policy $A$ pursues.

Equally $A$ may argue that if he chooses a value of $p$ less than $\frac{5}{8}$ he will leave it open to his opponent to put $p^{\prime}=1$, so maximising his expectation at $2838-10 p$. While if he fixes $p$ at a value greater than $\frac{5}{8}, B$ may put $p^{\prime}=0$, and maximise his expectation at $2828+6 p$. $B$ 's possible advantage is thus minimised at 2831.75 (Fig. 2), when $p=\frac{5}{8}$, and it is then a matter of indifference what policy $B$ adopts. In fact, as a function of $p$ and $p^{\prime}, B^{\prime}$ s expectation is represented by an anticlastic surface, and if each player pursues his own advantage, the chances of the game are stabilised at the saddle.

It is a slightly unexpected feature that, in spite of the game going 


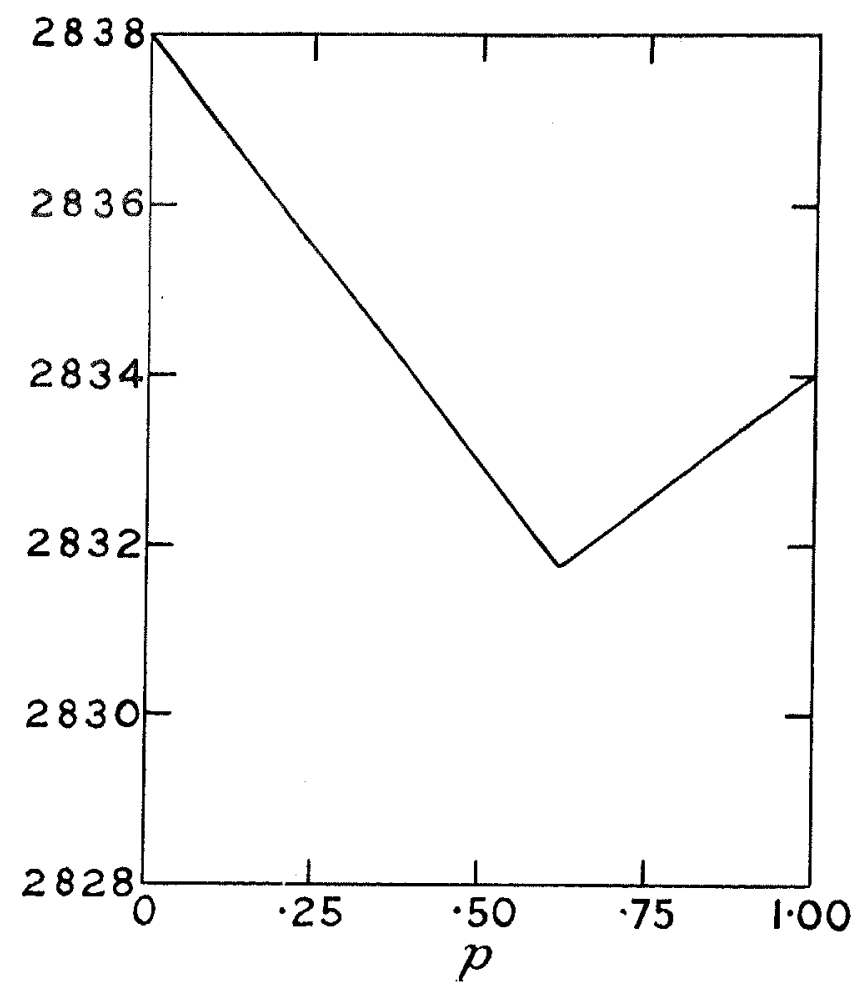

Fig. 2.

Maximal expectation of $B$ for different values of $p$.

to $A$ when the cards are equal, the chances should be on the whole to the advantage of $B$.

R. A. F. 